S.G. Buriakovskyi, A.S. Maslii, V.V. Panchenko, D.P. Pomazan, I.V. Denis

\title{
THE RESEARCH OF THE OPERATION MODES OF THE DIESEL LOCOMOTIVE CHME3 ON THE IMITATION MODEL
}

\begin{abstract}
Introduction. Fuel consumption by diesel locomotive during operation depends significantly on many factors, among which the main is the mode of driving a train. Purpose. Research on the mathematical model of the modes of driving a train on the site of Kharkiv-Merefa with the purpose of the main oscillograms of the operation of the locomotive on the site. Methodology. A mathematical model of the operation of the main units of the locomotive CHME3 in the Matlab environment was developed. The model of the diesel engine is based on the calculated indicator diagram of its operation, which is approximated by a continuous dependence. The control panel operates on a system of conditions, the purpose of which is to maintain the set speed. Results. In the course of the simulation, statistical data were obtained on the fuel consumption of the diesel locomotive when it operated on a section with a train of constant mass. Based on the data obtained, a three-dimensional surface is constructed showing the dependence of the fuel consumption on the time of the site's exploration and the maximum speed on the site. Practical value. The dependence obtained can be used to optimize the driving behavior of trains along a section. The apparent dependence of fuel consumption on the driver's behavior is the basis for the further development of automatic locomotive speed control systems. References 8, figures 6.

Key words: diesel locomotive, imitation model, diesel engine, traction electric drive, road profile, fuel consumption, train mode.
\end{abstract}

Разработана имитационная модель тепловоза ЧМЭЗ, которая состоит из дизеля с регулятором числа оборотов коленчатого вала, тягового генератора постоянного тока независимого возбуждения и тягового электрического привода. Проведено тестирование работы имитационной модели на профиле участка пути Харьков - Мерефа, при этом основными ограничениями являются время движения, для данного перегона не должно превышать 45 мин., а также максимальная допустимая скорость, которая для грузовых поездов составляет 80 км/ч. Получена трехмерная поверхность, которая показывает зависимость расхода топлива локомотива от режима ведения поезда машинистом при выполнении одинаковой работы, то есть одинакового времени движения по перегону. Библ. 8 , рис. 6. Ключевые слова: тепловоз, имитационная модель, дизель, тяговый электропривод, профиль пути, расход топлива, режим ведения поезда.

Introduction. Efficient use of fuel and energy resources is one of the most important tasks facing the Ukrainian economy. The Law of Ukraine «On Energy Saving» defines the energy efficiency of the economy as one of the main strategic guidelines for long-term state energy policy [1].

Railway transport is one of the largest energy consumers in the country. Energy efficiency in modern conditions is the most important factor in increasing the competitiveness of Ukrainian railways in the domestic and international transport services market. In 2010, the Cabinet of Ministers of Ukraine approved the Transport Strategy of Ukraine for the period up to 2020, aimed, in particular, at optimizing energy consumption in the unconditional performance of cargo transportation services and energy security of the company.

The main share of expenses of fuel and energy resources in the company accounts for traction of trains. Today it is $82 \%$ of the total consumption of electricity and $90 \%$ of diesel fuel [2]. Therefore, emphasis in energy saving is made, first of all, on the main type of activity the transportation process. In this regard, the issue of energy efficiency is very relevant for the railways and requires further research.

Analysis of literary data and problem definition. An overview [3] shows that CHME3 locomotives make up $97 \%$ of the entire fleet of shunting locomotives in the Ukrainian railways. In addition to maneuvering at stations, these locomotives are often used for transportation, as well as in the suburban traffic. In the conditions of the introduction of high-speed traffic, the optimization of the modes of data types of trains by sections is of particular importance. In conditions of increasing the speed of the passage of the site we should not forget about the cost of fuel and energy resources.

As noted in [4], the conditions of the locomotive operation while driving the trains are characterized by a continuous change in traction and speed, and to this also there are sections of the paths with insufficient grip. In this case, the power of the locomotive depends on many circumstances, it varies depending on the speed being implemented, the selected position of the controller of the driver and the degree of weakening of the excitation field. These circumstances allow us to implement very diverse modes of control of traction rolling stock, which often differ from those taken in the traction calculations and specified in the regime cards.

For various modes of operation, the rational driving conditions are essential. It does not allow to recommend one mode of driving a train as optimal for all practically possible traffic conditions in the area, because even on the same site, these conditions often change. In addition, the characteristics of electric machines and specific locomotives, depending on their technical state, may differ in certain respects from the corresponding passport data.

All this creates difficulties in the development and practical use of rational modes of driving trains. However, experience shows that even in the presence of regime maps and the implementation of recommended modes of driving trains, technically justified for some average operating conditions, actual costs of electricity and fuel from different drivers on

(c) S.G. Buriakovskyi, A.S. Maslii, V.V. Panchenko, D.P. Pomazan, I.V. Denis 
the same sites are different, deviations can be both greater and to a lesser extent than the established norm (up to $10 \%$ ).

Based on the above mentioned, one can conclude that studying the modes of driving a train is very important. Imitation modeling is the most appropriate way of research, since it enables to obtain important statistics with sufficient accuracy [5].

The goal and tasks of the research. The goal of the work is to investigate various modes of driving a train by CHME3 diesel locomotive for their optimality in terms of time of passage of a site and fuel consumption.

To achieve this goal we need:

- to develop an imitation model of all components of the locomotive involved in the creation and implementation of traction force;

- to select and simulate the section of the path on which the research will be conducted;

- to identify train driving modes and explore each one.

Presentation of the main material. The diesel generator set together with the electrical part of the research object consists of the following basic structural elements: control panel, diesel with regulator of crankshaft speed, traction generator of direct current of the independent excitation and traction electric drive. The block diagram of such object of research is shown in Fig. 1.

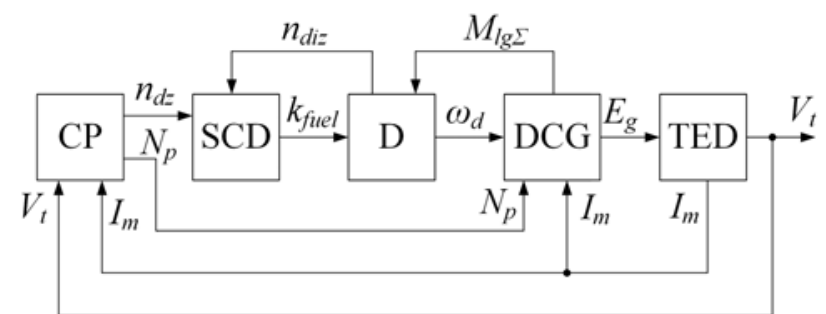

Fig. 1. Functional diagram of CHME3 diesel locomotive model: CP - control panel; SCD - diesel speed regulator; D - diesel;

DCG - DC generator with exciter; TED - traction electric drive

The input parameters for the CP unit are the train speed $V_{t}$ and the motor current $I_{m}$, on the value of which depend the driver's controller position number $N_{p}$ and the specified number of diesel turns $n_{d z}$ which is the input value for the SCD block. Depending on $n_{d z}$ and $n_{d i z}$, SCD determines the required amount of fuel $k_{f u e l}$. On the basis of $k_{f u e l}$ and loading torque $M_{l g \Sigma}$, DCG receives from $\mathrm{D}$ the value $\omega_{d}$. The value $E_{g}$ which is the input parameter of the TED block, is calculated by DCG depending on $N_{p}$ and $I_{m}$. At the output of TED, the value $V_{p}$ is formed.

The control panel $\mathrm{CP}$ of the diesel locomotive CHME3 has 8 positions of the voltage change on the traction motors and two positions of the field weakening. At each position, with the help of automatic regulators, the steady values of the frequency of rotation of the crankshaft of the diesel engine and of the voltage on the terminals of the exciter are maintained [6].

The modeled control panel switches the position of the driver's controller depending on two coordinates, namely: the current of engines and the speed of the train. The operation of the unit that simulates the panel is carried out under the following conditions:

$$
N_{p}=\left\{\begin{array}{l}
N_{p}-1 \text { if } I_{m}>I_{n} \vee V_{t}>V_{s} \\
N_{p} \text { if } I_{m}<I_{n} \wedge V_{s}-5 \leq V_{t} \leq V_{s}, \\
N_{p}+1 \text { if } I_{m}<I_{n} \wedge V_{t}<V_{s}-5
\end{array}\right.
$$

where $N_{p}$ is the position number of the driver's controller, $I_{m}$ is the current of the motor, $I_{n}$ is the rated current of the motor, $V_{t}$ is the current train's speed, $V_{S}$ is the specified train's speed.

To exclude the possibility of too frequent switching of positions, analysis of the need for switching occurs at intervals of $1 \mathrm{~s}$. To exclude a large number of switches in steady state, when the actual speed is close to the given, there is a dead zone of $5 \mathrm{~km} / \mathrm{h}$ in which there is no switching, and the movement is carried out on the previously selected position.

The block diagram realizing the condition (1) is shown in Fig. 2, where PS is the position selection block. The selected position number, also, is converted to a given speed of the diesel engine $n_{d z}$.

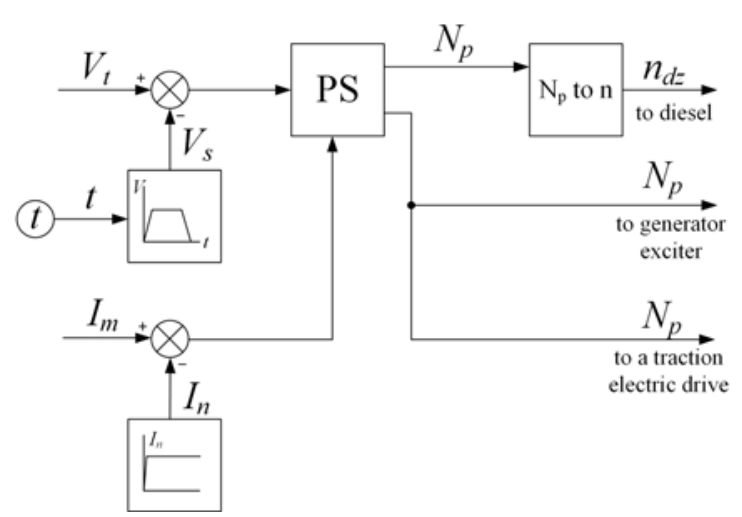

Fig. 2. The block diagram of the control panel model

All diesel engines according to the nature of their operation are very sensitive to load changes. An increase in diesel loading causes a reduction in the speed of the crankshaft («drawdown»), which can lead to the stopping of the diesel engine, and a decrease in the load is accompanied by a sharp increase in the rotational speed of the shaft, that is, the diesel engine can go to «spacing» [7].

In order to maintain constant rotational speed of the shaft under variable load conditions, a special regulator is required which automatically controls the fuel pumps. Mounted on a diesel K6S310DR a centrifugal inverted indirect action regulator protects it from overload performing the functions of the power regulator. The combined regulator can be represented as the PI regulator of the rotation speed of the crankshaft of the diesel engine, the input value of which is the amount of fuel that needs to be fed into the cylinder.

As the basis of the simulation model of the diesel, indicator diagram of its operation is used. The process taking place in the cylinder of the piston engine can be presented as a indicator diagram. Indicator diagram is the extreme reflection of pressure change of gas in the cylinder of the piston engine depending on the piston displacement or the turn angle of the crank [8]. For the K6S310DR diesel engine, the indicator diagram of its operation is calculated and built. The indicator diagram is 
built as a dependence of the change in pressure $P$ in the engine's cylinder on the change in volumes $V$ during the piston's displacement.

For the diesel model, the use of the diagram in the axes $P$ and $V$ is rather uncomfortable, so the diagram is transformed into a diagram in the axes $F$ and $S$, where $F$ is the force acting on the piston, $S$ is the displacement of the piston. The dependence diagram of the force acting on the piston on the displacement is shown in Fig. 3.



Fig. 3. Operation diagram of the diesel engine K6S310DR

The locomotive has a generator that is a ten-pole DC motor with independent excitation. The power supply of the independent excitation winding of the generator is carried out from the exciter - a machine of direct current connected by a shaft with auxiliary generator.

The block that simulates the traction electric drive includes, in addition to the traction electric motor, blocks that simulate the train's motion in the section and braking of a train.

The model of the resistance blocks of the train's movement is made according to the empirical formulas for the locomotive and cars. The profile of the section Kharkiv-Merefa has been used as a profile of the road. The input parameter for the slope selection block is the path that traveled, which is obtained by integrating the speed of the train.

Input variables for the braking unit operation are the given speed $V_{s}$, the current train speed $V_{t}$, and the position number of the locomotive driver's controller $N_{p}$. To exclude the mode at which braking occurs with operating traction motors, the check of the current position of the handle of the driver's controller is performed. If the position is non-zero, braking does not occur.

The testing of the imitation model was carried out under the parameters given above. Here, the main restrictions were the time of travel, which for the Kharkiv-Merefa section should not exceed 45 minutes, as well as the maximum permissible speed, which for freight trains is $80 \mathrm{~km} / \mathrm{h}$. Taking this into account, it is possible to use different intensity of acceleration of the train with the subsequent maintenance of the average speed of the run. Fig. 4 shows two types of train traction tachograms.

In the tachograms shown, $t_{d}$ is the run-time, which is the same for two tachograms. The change in the intensity of the train's acceleration leads to a change in the maximum speeds that are shown in the diagrams shown as $V_{m 1}, V_{m 2}$. In the software package Matlab, using a mfile, a subroutine was written in which the calculation of the intensity of acceleration and train's braking depending on a given maximum speed was performed, subject to the observance of the driving time of the run. In the study of the operation of the train on the imitation model, tachographs with maximum speeds in the range of $40-80 \mathrm{~km} / \mathrm{h}$ with step $10 \mathrm{~km} / \mathrm{h}$ were set. Fig. 5 shows the oscillograms of the shunting diesel locomotive operation with 10 cars, at a maximum speed of $60 \mathrm{~km} / \mathrm{h}$.
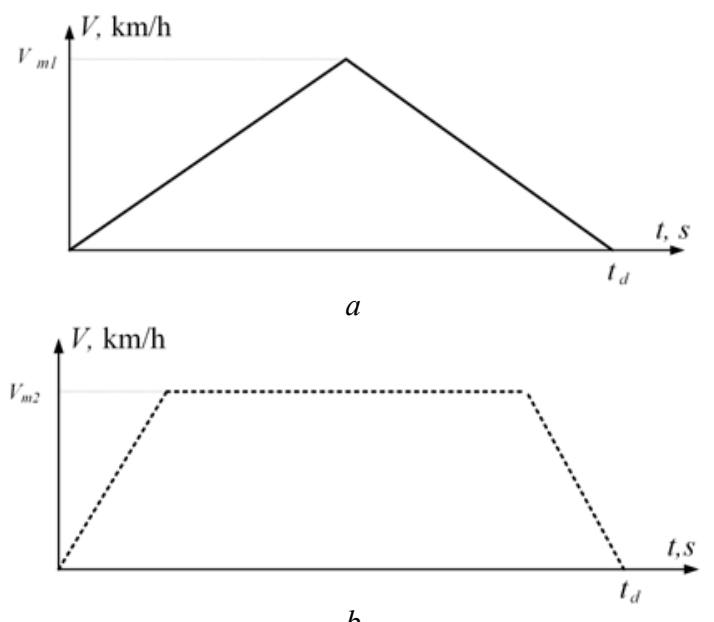

Fig. 4. Types of tachograms of the train acceleration: $a$ - triangular; $b$ - trapezoidal
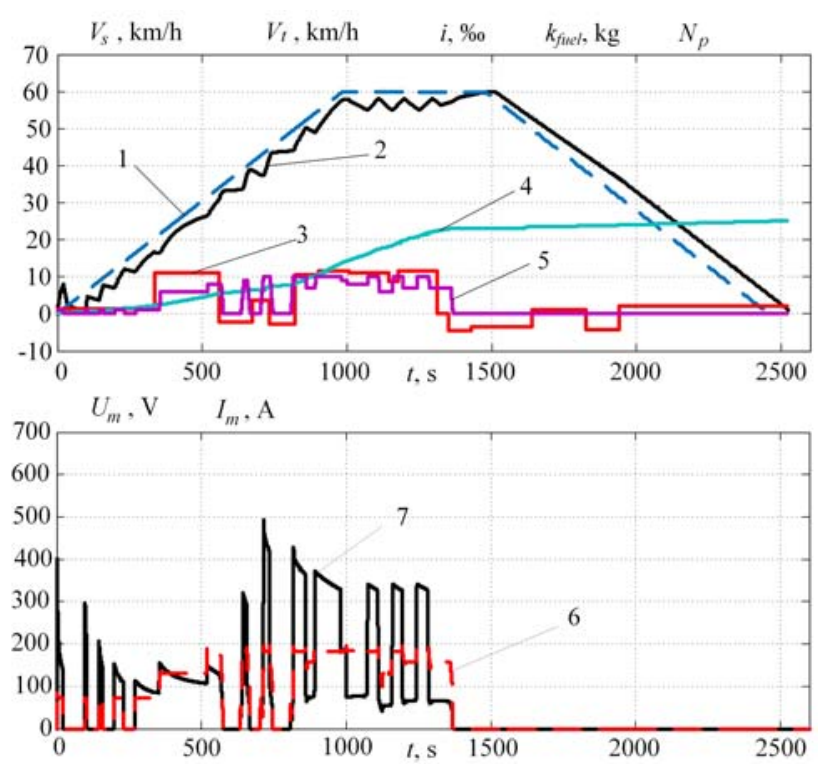

Fig. 5. Oscillograms of the locomotive operation at a maximum speed of $60 \mathrm{~km} / \mathrm{h}: 1$ - a tachogram is given; 2 - real speed of the train; 3 - profile of the path; 4 - fuel consumption; 5 - position number of the driver's controller; 6 - voltage on the traction motor; 7 - current of the traction motor

On the obtained oscillograms curve 3 shows the process of set of positions, which varies with different values of maximum speed. Each position corresponds to the change in the voltage on the traction motors (curve 6) and the values of current (curve 7) in them, which was limited to $600 \mathrm{~A}$. The graphs show a tendency to increase fuel consumption with an increase in maximum speed, which requires a more detailed study. Changing the maximum speed of a triangular diagram in the range of $70-95 \mathrm{~km} / \mathrm{h}$ with step of $5 \mathrm{~km} / \mathrm{h}$ the results presented in the form of a three-dimensional surface were obtained (Fig. 6). 




Fig. 6. Changing the fuel consumption depending on the maximum speed of the given diagram

The resulting surface confirms the dependence of the fuel consumption on the locomotive on the train driver's mode of driving (on the time the locomotive operation at a certain position and the intensity of the transition from position to position) when performing the same work, that is, the same time of movement on the run. The smallest fuel consumption, namely $29-31 \mathrm{~kg}$, takes place when the maximum speed is set at $40-50 \mathrm{~km} / \mathrm{h}$. Therefore, there is a need to optimize the given train tachogram and develop an automatic control system using a speed regulator that more accurately worked out such a tachogram.

Conclusions. An imitation model of the diesel locomotive CHME3, consisting of a control panel, a diesel engine with a crankshaft speed regulator, an independent excitation DC traction generator and a traction electric drive with sequential excitation DC motors, has been developed. An algorithm is created that simulates the work of the driver, that is, it switches the positions of the controller and controls the brakes. The modeling of the diesel engine is based on the indicator diagram of its operation, which is approximated by continuous dependencies. The obtained imitation model allows obtaining important statistical data for conducting analysis of train driving modes.

A number of operation modes investigations have been carried out when changing the tachogram of speed. Changing the maximum speed of a triangular diagram in the range of $70-95 \mathrm{~km} / \mathrm{h}$ with step of $5 \mathrm{~km} / \mathrm{h}$ oscillograms of the locomotive operation with a constant loading on the real section of the road Kharkiv-Merefa are obtained.

From the oscillograms it is seen that the current during motion of the site was lower than the nominal, and in peak modes reached $500 \mathrm{~A}$. Time of passage of the site with a given acceleration rate and speed limit on the level $60 \mathrm{~km} / \mathrm{h}$ was $2530 \mathrm{~s}$.

The model includes a block that calculates fuel consumption by diesel locomotive. Based on the data obtained from the simulation, a three-dimensional surface is constructed, which reflects the dependence of fuel consumption on the time of the passage of the site and the maximum speed. It has been established that the smallest fuel consumption, namely $29-31 \mathrm{~kg}$, occurs when the maximum speed is set at $40-50 \mathrm{~km} / \mathrm{h}$.

The results obtained during the study show that there is a need to create an automatic control system using a speed controller that more accurately worked out the given tachogram, as well as optimization of train driving modes.

\section{REFERENCES}

1. Available at: http://www.uz.gov.ua/en/about/general information (accessed 08 May 2017).

2. Efimenko Yu.I., Kovalev V.I., Loginov S.I. Zheleznyie dorogi. Obschiy kurs [Railways. General course]. Moscow, UMC ZhDT Publ., 2014. 503 p. (Rus).

3. Kulaev Yu.F. EkonomIka zallznichnogo transportu. Navchalniy posibnik [The Economics of Railway Transport. A Textbook]. Nizhyn, Aspect. Poligraph Publ., 2006. 232 p. (Ukr).

4. Franzitta V., Curto D., Milone D., Trapanese M. Energy Saving in Public Transport Using Renewable Energy. Sustainability, 2017, vol.9, no.12, p. 106. doi: 10.3390/su9010106.

5. Velten K. Mathematical Modeling and Simulation. WileyVCH Verlag GmbH \& Co. KGaA, Weinheim, Germany, 2008. doi: 10.1002/9783527627608.

6. Buryakovs'kyy S.H., Masliy A.S., Pomazan D.P., Denys I.V. Rationale for modernization of diesel locomotives CHME3 using hybrid propulsion system. Electrification of Transport, 2016, no.12, pp. 82-86. (Ukr).

7. Xin Q. Engine-vehicle matching analysis in diesel powertrain system design. Diesel Engine System Design, 2013, pp. 348-394. doi: 10.1533/9780857090836.2.348.

8. Diesel Engine. Van Nostrand's Scientific Encyclopedia. John Wiley \& Sons, Inc., 2005. doi: 10.1002/0471743984.vse2527.

Received 13.02.2018

S.G. Buriakovskyi ${ }^{1}$, Doctor of Technical Science,

A.S. Maslii ${ }^{2}$, Candidate of Technical Science, Associate

Professor,

V.V. Panchenko ${ }^{2}$, Candidate of Technical Science, Associate

Professor,

D.P. Pomazan ${ }^{2}$, Postgraduate Student,

I.V. Denis ${ }^{3}$,

${ }^{1}$ Scientific-\&-Research Planning-\&-Design Institute «Molniya»,

National Technical University «Kharkiv Polytechnic Institute»,

2, Kyrpychova Str., Kharkiv, 61002, Ukraine,

e-mail: sergbyr@i.ua

${ }^{2}$ Ukrainian State University of Railway Transport,

7, Feierbakh Square, Kharkiv, 61050, Ukraine,

e-mail: a.masliy@ukr.net,vlad_panchenko@ukr.net, danil.pomazan@ukr.net

${ }^{3}$ PJSC «CARTEL»,

84a, Dnieper highway Str., Kriviy Rig, 50026, Ukraine, e-mail: div99@ukr.net

How to cite this article:

Buriakovskyi S.G., Maslii A.S., Panchenko V.V., Pomazan D.P., Denis I.V. The research of the operation modes of the diesel locomotive CHME3 on the imitation model. Electrical engineering \& electromechanics, 2018, no.2, pp. 59-62. doi: 10.20998/2074-272X.2018.2.10. 